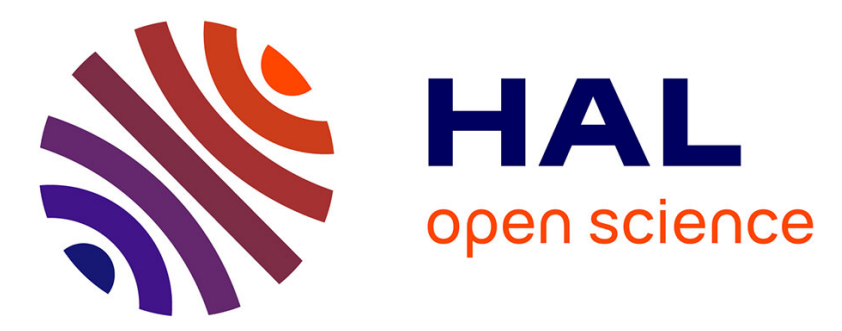

\title{
Advanced magnetic calculations for high magnetic field compact ion source
}

\author{
T. Thuillier, J.C. Curdy, T. Lamy, P. Sole, P. Sortais, J.L. Vieux-Rochaz, D. \\ Voulot
}

\section{> To cite this version:}

T. Thuillier, J.C. Curdy, T. Lamy, P. Sole, P. Sortais, et al.. Advanced magnetic calculations for high magnetic field compact ion source. International Conference on Ion Sources 10 ICIS 03, Sep 2003, Dubna, Russia. pp.1526-1528. in2p3-00020414

\section{HAL Id: in2p3-00020414 https://hal.in2p3.fr/in2p3-00020414}

Submitted on 5 Feb 2004

HAL is a multi-disciplinary open access archive for the deposit and dissemination of scientific research documents, whether they are published or not. The documents may come from teaching and research institutions in France or abroad, or from public or private research centers.
L'archive ouverte pluridisciplinaire HAL, est destinée au dépôt et à la diffusion de documents scientifiques de niveau recherche, publiés ou non, émanant des établissements d'enseignement et de recherche français ou étrangers, des laboratoires publics ou privés. 


\title{
Advanced magnetic calculations for high magnetic field compact ion source
}

\author{
T. Thuillier, J.-C. Curdy, T. Lamy, P. Sole, P. Sortais, J.-L. Vieux-Rochaz and D. Voulot \\ Laboratoire de Physique Subatomique et de Cosmologie, Grenoble 38026, France
}

\begin{abstract}
The design of the new advanced ECRIS requires relatively high axial and radial magnetic inductions to allow the ECR frequency increase and to take advantage of the subsequent density increase (scaling laws). The last improvements of the commercial rare earth magnets characteristics open new opportunities for ECRIS and enable to design very high hexapolar magnetic fields for next generation compact ECRIS. Moreover, the High Temperature Superconducting (HTS) wires allow designing reliable and compact axial field coils $(30 \mathrm{~K}$ cooled) at a very effective cost. It is thus very relevant to study a compact hybrid ECRIS using high remanence magnet and HTS technologies. In such a design, the volume of the plasma chamber is a free parameter that can be adjusted to the user requirement. It can be dedicated to very high ionic current production or high charge state production, pulsed or $\mathrm{CW}$ operations.

This paper presents the 3D overall simulation of a 3 Tesla axial magnetic field compact ECRIS with a high radial field sextupole composed with several magnet types and reaching $\sim 1.9 \mathrm{~T}$ in front of the radially magnetized magnets. This design study will lead to the building of the 28$40 \mathrm{GHz}$ A-PHOENIX source at the laboratory which will deliver its first beam by the end of 2004.
\end{abstract}

\section{Introduction}

This paper presents a simulation study of an hybrid ECRIS based on updated permanent magnet technology to generate the radial sextupolar confinement and HTS wire technology for axial field. The 3D non-linear calculations have been performed with the
RADIA[1] package of Mathematica@. The overall ECRIS structure of A-PHOENIX is drawn on figure 1 , while a $3 \mathrm{D}$ plot of the simulation program is available on figure 2 .

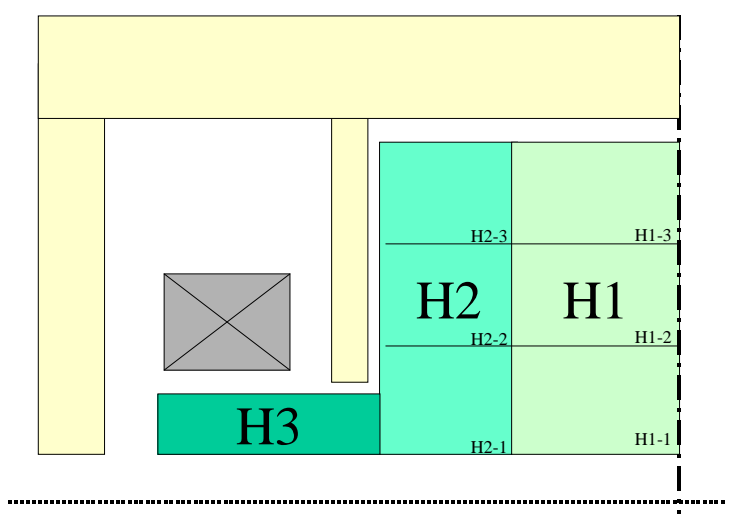

Figure 1 : sketch view of $1 / 4$ of the simulated ECRIS.

\section{High Temperature Superconducting Coil}

The HTS technology is today mature and reliable and can be sagely used on ECRIS. Its major advantage with respect to classical SC devices is that cooling is performed by thermal conduction with a simple industrial cryocooler with working points around 20 to 30 Kelvins. The first HTS Coils dedicated to ECRIS have been ordered to Space Cryogenics LTD by Pantechnik to be mounted on the PK-DELY ECRIS[2]. The technical datasheets for HTS superconductors wires is available on American Superconductors (AMS) web site[3]. The coils simulated in this paper relies on the "High Strength Wire" of AMS, based on Bi-2223 technology. The wire is $0.3 \mathrm{~mm}$ thick and $4 \mathrm{~mm}$ wide and can handle up to $\sim 263 \mathrm{Mpa}$ stress at $77 \mathrm{~K}$. HTS coil is composed with a set of elementary pancakes with an elementary axial width of $\sim 10 \mathrm{~mm}$, a 
minimum inner diameter of $70 \mathrm{~mm}$ and a free outer one.

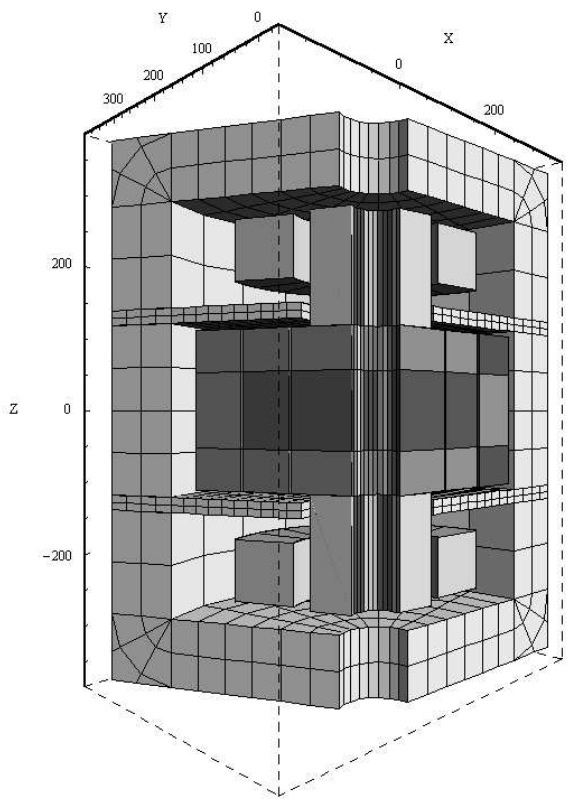

Figure 2 : Cross section of the ECRIS simulated with RADIA.

In the present paper, the simulated ECRIS is equipped with two iron shielded coils with inner and outer diameter respectively $220 \mathrm{~mm}$ and 370 $\mathrm{mm}$ and an axial height of $80 \mathrm{~mm}$. The magnetic field reaches $\sim 3 \mathrm{~T}$ on axis for a current density of $80 \mathrm{~A} / \mathrm{mm} 2$ (see figure 3 for axial profile on ECRIS axis). The width of the mirror trap is 410 $\mathrm{mm}$. The hoop stress is maximum on the inner diameter of the coil with $\sigma=\mathrm{B} \times \mathrm{J} \times \mathrm{R} \sim 35 \mathrm{MPa}$. This last value is very small with respect to the critical stress of 263 Mpa. The limit for superconductivity regime comes from the maximum magnetic field wire can bear as a function of carried current for a given temperature. This point is illustrated on figure 4 where AMS wire performances for magnetic field perpendicular to the wire tape (radial magnetic field component) is plotted as a function of the critical current for several temperatures. The maximum radial magnetic field in the coils is $\mathrm{Br} 2 \mathrm{~T}$ for a current density of $80 \mathrm{~A} / \mathrm{mm} 2$ (I 155 A in wire). The coil load line has been reported on figure 4 , so one can see that a cryostat cooling down to $25-30 \mathrm{~K}$ will insure the superconductivity condition. The same kind of check is done with magnetic field parallel to the tape, but here, the condition is less drastic and the maximum of $4 \mathrm{~T}$ calculated in the coil is well below the acceptable limit at $30 \mathrm{~K}$.

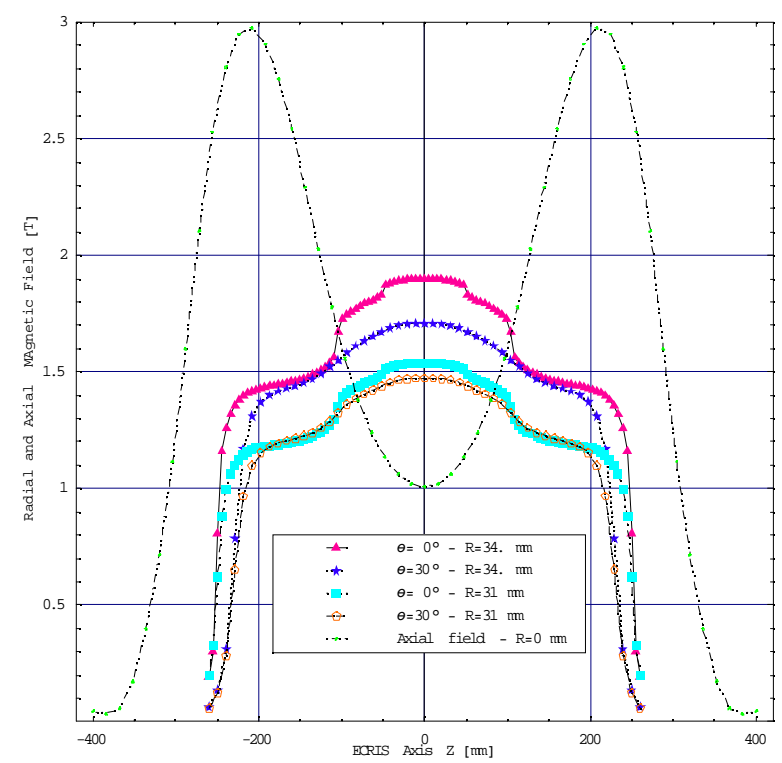

Figure 3: Radial Magnetic confinement along the axis of ECRIS axis in front of the magnets $(\mathrm{R}=34 \mathrm{~mm})$ and at the inner edge of the plasma chamber $(\mathrm{R}=31 \mathrm{~mm})$. Last plot is the Axial magnetic profile at $\mathrm{R}=0$ with a current density of $80 \mathrm{~A} / \mathrm{mm}^{2}$ in each coil.

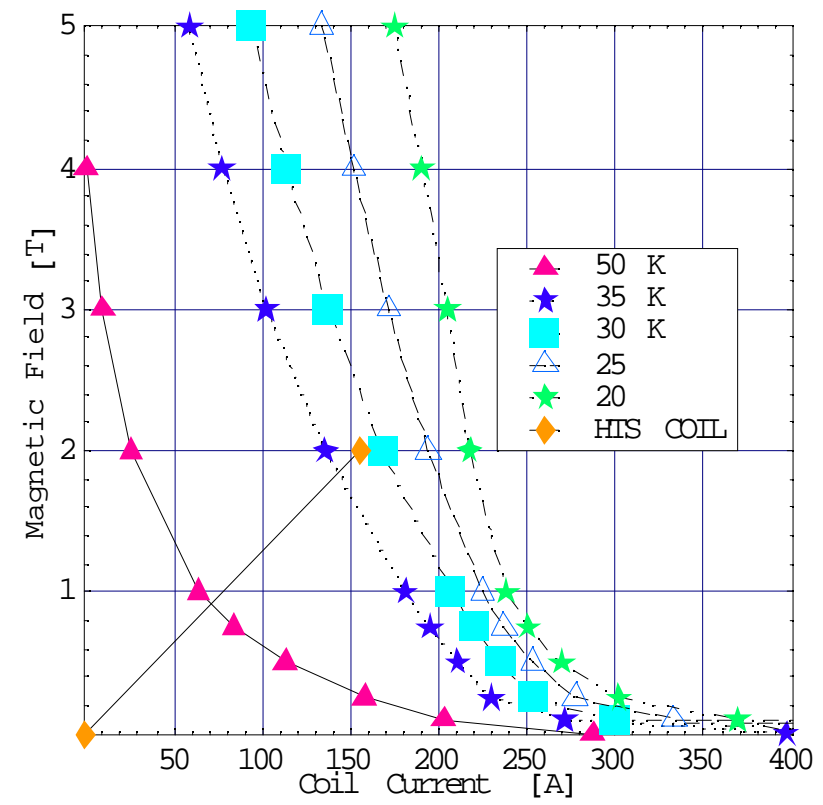

Figure 4: AMS Bi-2223 performance for magnetic field perpendicular to the wire. See text. 


\section{The high magnetic field sextupole}

The up to date commercial magnets offers new interesting opportunities for hallbach type sextupoles. Thus, some years ago, atomic physicists made up a $1.6 \mathrm{~T}$ sextupole with Vacuum Schmeltze products[4]. See Table 1 for an overview of the magnetic properties of permanent magnets from this company[5].

Table 1 : Magnet properties available fromVacuum Schmeltze datasheet[5].

\begin{tabular}{|c|c|c|c|c|c|c|c|c|}
\hline \multirow{3}{*}{$\begin{array}{l}\text { Materi } \\
\text { al } \\
\text { Code }\end{array}$} & \multicolumn{4}{|c|}{ Remanence [kG] } & \multicolumn{4}{|c|}{$\begin{array}{l}\text { Coercivity } \\
\mathbf{H}_{\text {cJ }}[\mathrm{kOe}]\end{array}$} \\
\hline & \multicolumn{2}{|l|}{$20^{\circ} \mathrm{C}$} & \multicolumn{2}{|c|}{$40^{\circ} \mathrm{C}$} & \multicolumn{2}{|c|}{$20^{\circ} \mathrm{C}$} & \multicolumn{2}{|l|}{$40^{\circ} \mathrm{C}$} \\
\hline & Typ. & Min. & Typ. & Min. & Typ. & Min. & \begin{tabular}{|l|} 
Typ. \\
\end{tabular} & Min. \\
\hline $722 \mathrm{HR}$ & 14.7 & 14.2 & 14.4 & 13.9 & 12 & 11 & 9.5 & 8.7 \\
\hline $745 \mathrm{HR}$ & 14.4 & \begin{tabular}{|l|}
14.0 \\
\end{tabular} & 14.0 & \begin{tabular}{|l|}
13.7 \\
\end{tabular} & 15 & 14 & 12.2 & 11.3 \\
\hline $633 \mathrm{HR}$ & 13.5 & 12.9 & 13.2 & 12.6 & 18 & 16 & 15.4 & 14.2 \\
\hline $655 \mathrm{HR}$ & 12.8 & 12.2 & 12.6 & 12 & 23 & 21 & 20 & 18.7 \\
\hline $677 \mathrm{HR}$ & 11.8 & 11.2 & 11.6 & 11 & 31 & 28 & 28 & 25.2 \\
\hline
\end{tabular}

Below, any reference to sextupole will refer to Hallbach permanent magnet sextupole made up with 36 magnets distributed azimuthally on $2 \pi$. In this case, the magnetization axis of individual magnets with respect to the local azimuthal direction is referred here as $\theta_{M}=0,30,60$ and $90^{\circ}$, where $\theta_{\mathrm{M}}=0$ stands for a magnetization axis perpendicular to the plane of symmetry of the magnet.

High coercitivity magnets, such as VACODYM $655 \mathrm{HR}$, enables to build large radius sextupoles, but the usable magnetic field is quickly limited as a function of outer radius to $\sim 1.7 \mathrm{~T}$ for $\mathrm{R} \sim 250$ $\mathrm{mm}$. On the other hand, high remanence magnets, such as VACODYM 633 and 745 HR, enables to build very compact sextupole providing 1.3 to $1.5 \mathrm{~T}$ for small outer radii. But for higher radius, these last species starts to demagnetise themselves, especially for $\theta_{M}=0^{\circ}$ near inner radius and for $\theta_{M}=90^{\circ}$ for outer radius. Nevertheless, the inverse induction field seen by individual magnets depends strongly on $\theta_{M}$ and local radius in the sextupole. So it is possible to keep high remanence magnets in a large radius sextupole where the inverse field is low and use high coercivity magnets where inverse field is high. This strategy was applied for the design of the simulated sextupole. Thus, the radial field is made up with 3 types of sextupoles named $\mathrm{H} 1, \mathrm{H} 2$ and $\mathrm{H} 3$ (see figure 1). H1 contains 3 concentric crowns of permanent magnets with radii $35<\mathrm{R}_{1}<115,119<\mathrm{R}_{2}<182$, $186<\mathrm{R}_{3}<250 \mathrm{~mm}$ respectively. $\mathrm{H} 1$ extends axially from $-50<\mathrm{Z}<50 \mathrm{~mm}$ and is dedicated to maximize the radial magnetic field in the center of the plasma chamber. $\mathrm{H} 2$ has the same type of structure as $\mathrm{H} 1$ but is made up with more coercitive magnets in order to resist the additive $\mathrm{Br}$ component generated by the coils. It is placed symmetrically on the right and on the left of $\mathrm{H} 1$ at $105>|Z|>50$. Note on figures 1 and 2 the 20 $\mathrm{mm}$ iron disc shield between the coils and $\mathrm{H} 2$ to minimize the coil fringe field effects on magnets. H3 is located directly under the coil and is composed of one crown of very coercitive magnets in order to hold the main magnetic field of the coils. This structure enables to adapt accurately the magnetic induction load, magnet by magnet, in order to maximize the magnetic field in the plasma chamber. The result of this optimisation is summarized in Table 2.

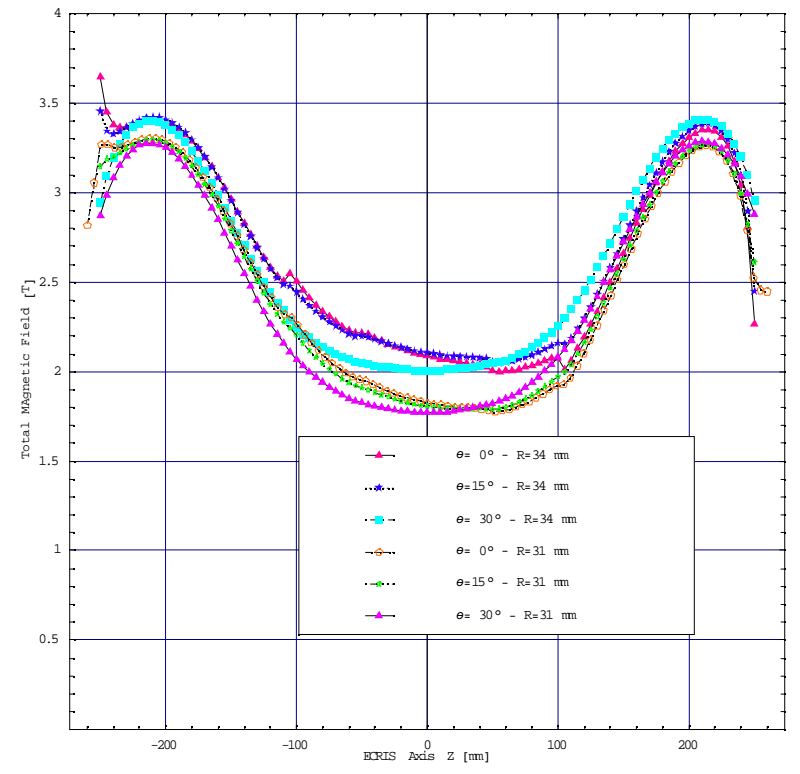

Figure 5 : Total magnetic field along the ECRIS axis for several radius and azimuthal angles. 
Table 2: Characteristics of the magnets forming the sextupoles $\mathrm{H} 1, \mathrm{H} 2, \mathrm{H} 3$. Hmax is the maximum magnetic induction seen by an individual magnet along its magnetization axis. (*Magnets selected as having typical coercitivity at $40^{\circ} \mathrm{C}$ ).

\begin{tabular}{|c|c|c|c|c|}
\hline $\begin{array}{l}\boldsymbol{\theta}_{\mathrm{M}} \\
{\left[^{\circ}\right]}\end{array}$ & $\begin{array}{l}\text { Magne } \\
\text { t } \\
\text { code }\end{array}$ & $\begin{array}{l}\text { Crown } \\
\#\end{array}$ & $\begin{array}{l}\mathbf{H}_{\max } \\
{[\mathrm{T}]}\end{array}$ & $\begin{array}{l}\text { Magnet } \\
\text { Load at } \\
40^{\circ} \mathrm{C} \\
{\left[\mathrm{H}_{\max } / \mathrm{H}_{\mathrm{cJm}}\right.} \\
\text { in.] }\end{array}$ \\
\hline 0 & $677 \mathrm{HR}$ & H1-1 & -1.86 & $-73 \%$ \\
\hline 0 & $655 \mathrm{HR}$ & H1-2 & -1.35 & $-72 \%$ \\
\hline 0 & $745 \mathrm{HR}$ & H1-3 & -0.81 & $-71 \%$ \\
\hline 30 & $633 \mathrm{HR}$ & H1-1 & -1.3 & $-84 \% *$ \\
\hline 30 & $633 \mathrm{HR}$ & H1-2 & -1.11 & $-78 \%$ \\
\hline 30 & $745 \mathrm{HR}$ & H1-3 & -0.79 & $-70 \%$ \\
\hline 60 & $722 \mathrm{HR}$ & H1-1 & -0.2 & $-23 \%$ \\
\hline 60 & $722 \mathrm{HR}$ & H1-2 & -0.69 & $-79 \%$ \\
\hline 60 & $633 \mathrm{HR}$ & H1-3 & -1.03 & $-72 \%$ \\
\hline 90 & $722 \mathrm{HR}$ & H1-1 & +0.5 & $0 \%$ \\
\hline 90 & $722 \mathrm{HR}$ & H1-2 & -0.67 & $-77 \%$ \\
\hline 90 & $655 \mathrm{HR}$ & H1-3 & -1.28 & $-76 \%$ \\
\hline 0 & $677 \mathrm{HR}$ & H2-1 & -1.83 & $-72 \%$ \\
\hline 0 & $655 \mathrm{HR}$ & H2-2 & -1.26 & $-67 \%$ \\
\hline 0 & $745 \mathrm{HR}$ & H2-3 & -0.75 & $-66 \%$ \\
\hline 30 & $633 \mathrm{HR}$ & H2-1 & -1.35 & $-87 \% *$ \\
\hline 30 & $633 \mathrm{HR}$ & H2-2 & -1.12 & $-79 \%$ \\
\hline 30 & $745 \mathrm{HR}$ & $\mathrm{H} 2-3$ & -0.8 & $-71 \%$ \\
\hline 60 & $633 \mathrm{HR}$ & H2-1 & -0.99 & $-70 \%$ \\
\hline 60 & $745 \mathrm{HR}$ & H2-2 & -0.94 & $-83 \%$ \\
\hline 60 & $633 \mathrm{HR}$ & $\mathrm{H} 2-3$ & -1.05 & $-74 \%$ \\
\hline 90 & $745 \mathrm{HR}$ & H2-1 & -0.91 & $-80 \%$ \\
\hline 90 & $633 \mathrm{HR}$ & H2-2 & -1.03 & $-73 \%$ \\
\hline 90 & $655 \mathrm{HR}$ & H2-3 & -1.3 & $-69 \%$ \\
\hline 0 & $655 \mathrm{HR}$ & H3 & -1.63 & $-87 \%$ \\
\hline 30 & $655 \mathrm{HR}$ & H3 & -1.29 & $-77 \%$ \\
\hline 60 & \begin{tabular}{|l}
$677 \mathrm{HR}$ \\
\end{tabular} & H3 & -1.87 & $-74 \%$ \\
\hline 90 & $677 \mathrm{HR}$ & $\mathrm{H3}$ & -2.15 & $-85 \%$ \\
\hline
\end{tabular}

Figure 3 includes profiles of the radial magnetic field along the ECRIS axis for $\mathrm{R}=34$ $\mathrm{mm}$ and $\mathrm{R}=31 \mathrm{~mm}$ for two azimuthal angles $\left(\theta=0^{\circ}\right.$ stands for $\theta_{M}=90^{\circ}$ magnet type and $\theta=30^{\circ}$ stands for $\theta_{\mathrm{M}}=0^{\circ}$ ). The individual contribution of the 3 sextupoles $\mathrm{H} 1, \mathrm{H} 2, \mathrm{H} 3$ is clearly visible. The highest magnetic field is located under $\mathrm{H} 1$ : a Hall probe placed in front of $\theta_{M}=90^{\circ}$ magnets will measure $\sim 1.9 \mathrm{~T}$, while $1.7 \mathrm{~T}$ is available in front of a $\theta_{M}=0^{\circ}$ ones. The radial magnetic field in the inner edge of the plasma chamber $(r=31$ $\mathrm{mm}$ ) is $\sim 1.5 \mathrm{~T}$. The slight decrease in the radial magnetic profile for $|\mathrm{Z}|>50 \mathrm{~mm}$ correspond to $\mathrm{H} 2$ with an average of $\sim 1.7 \mathrm{~T}$ at $\mathrm{r}=34 \mathrm{~mm}$. Then for $|\mathrm{Z}|>105$ stands the $\mathrm{H} 3$ sextupole with still 1.4 $\mathrm{T}$ at $\mathrm{r}=34 \mathrm{~mm}$. This radial magnetic decrease is fully balanced by the subsequent increase of the axial magnetic field toward the coils so that the total magnetic field remains smooth as it can be seen in figure 5 . The magnetic intensity is superior to $2 \mathrm{~T}$ along the whole length of the ECRIS for $\mathrm{r}=34 \mathrm{~mm}$. The magnetic intensity remains at the level of $\sim 1.8 \mathrm{~T}$ at the edge of the plasma chamber. The whole sextupole is secured for a daily working temperature of $\sim 40^{\circ} \mathrm{C}$. If one can buy a sample of "typical" properties magnets and discard those with "minimum" specifications, it is possible to increase the mean magnetic induction up to $1.85 \mathrm{~T}$ by replacing some high coercitivity magnets by high remanence one. This second result was obtained with an inner radius of $45 \mathrm{~mm}$ while the outer remained at $250 \mathrm{~mm}$. It underlines that this high level of magnetic field can be achieved with an arbitrary fixed inner radius.

\section{References}

[1] P. Elleaume et $A l$, presented at the PAC97 Conf. May 1997, Vancouver.

[2] S. Kantas et Al., Recent developments in ECR sources, Proc. ICIS 03, Dubna.

[3] American Superconductor web site : http://www.amsuper.com

[4] Rev. Sci. Instrum., Vol. 17,\# 9, Sept. 2000

[5] Rare-Earth Permanent Magnets, VACODYM VACOMAX, Company Information Booklet PD-002, Ed. 2000, Vacuumschmeltze GmbH, P.O.B. 22 53, D-63412 Hanau, Germany p.1222, http://www.vacuumschmelze.de/. 